\title{
Short-Term Deformation Monitoring Analysis for a Large Span Cable Stayed Bridge
}

\author{
Mao YANG ${ }^{1}$, Hu MA ${ }^{2}$, Qianying $Z_{E N G}^{3}$, Jingjing YANG ${ }^{1}$ \& Zengshun $\mathrm{CHEN}^{1}$ \\ ${ }^{1}$ School of Civil Engineering \& Architecture, Chongqing Jiaotong University, Chongqing, China \\ ${ }^{2}$ Chongqing Rail Transit (Group) Co. Ltd., Chongqing, China \\ ${ }^{3}$ School of Management, Chongqing Jiaotong University, Chongqing, China \\ Correspondence: Zengshun CHEN, School of Civil Engineering \& Architecture, Chongqing Jiaotong University, \\ Chongqing 400074, China. E-mail: chenzs2007@163.com
}

Received: March 30, 2014

Accepted: August 24, $2014 \quad$ Online Published: September 4, 2014

doi:10.5539/mas.v8n6p37

URL: http://dx.doi.org/10.5539/mas.v8n6p37

\begin{abstract}
Based on a large span cable-stayed bridge in Chongqing, this paper analyzes the bridge alignment, vertical displacement and deviation of cable tower, expansion joint deformation and cable force during operation. The study calculates related theoretical values of bridge deformation by using finite element software. The security situation of the bridge is then evaluated on the foundation of contrastive analysis of the calculated values and measured values, which provides some basis for similar bridge monitoring.
\end{abstract}

Keywords: large span cable stayed bridge, theoretical values, measured values, security situation

\section{Introduction}

In recent years, with booming of large span bridge construction, bridge health monitoring and evaluation technology has become a research hotspot for scholars across the world and has been widely used in engineering practice. With advantages of high economical efficiency, fine rigidity and wind stability, cable-stayed bridge has always been one of the main forms of long-span bridges. However, with the development of society, requirements for transport capacity are rising and a lot of actual bridge carriage capacity surpasses the design value, resulting in severe function degradation and large deformation of bridges, therefore, bridge structure deformation monitoring is particularly important.

Document 1 investigates safety assessment of cable-stayed bridges while Document 2 Document 5 emphasizes methods that used GPS or smart sensors to do deformation monitoring. Document 6 proposes a new finite element model updating method of monitoring data analysis. Document 7 and Document 8 investigates cable tension monitoring and control. Studies are carried out on the cable-stayed bridge safety monitoring in China and abroad, however, the monitoring content is not comprehensive and few studies have carried out comparative analysis on large span cable-stayed bridge deformation monitoring. This paper uses manual measurement, which is more flexible and more suitable for short-term monitoring, to obtain deformation data. Then uses finite element software to analyze the calculated deformation theoretical values of a large span cable-stayed bridge, and carries out comparative analysis on the field monitoring measured values and the calculated theoretical values to obtain the conclusion of deformation monitoring. Analysis on deformation monitoring of this large span cable-stayed bridge can provide some basis for similar bridge monitoring and is thus of great popularization value.

\section{Project Overview}

A large span cable-stayed bridge is located at G42 Hurong expressway, section Wushan to Wanzhou in Chongqing with a total length of $816 \mathrm{~m}$, the main bridge of which is a twin towers twin ropes pre-stressed concrete cable-stayed bridge with a length of $766 \mathrm{~m}$. The span is $(43+147+386+147+43) \mathrm{m}$ (main bridge) $+2 \times$ $25 \mathrm{~m}$ (approach bridge). Deck transverse arrangement: $2 \mathrm{~m}$ (overhaul road + fence) $+10.75 \mathrm{~m}$ (lane) $+1.50 \mathrm{~m}$ (fence) $+10.75 \mathrm{~m}$ (lane) $+2 \mathrm{~m}$ (overhaul road + fence) .

Double rib sections are adopted for the main girder standard sections on the superstructure of the main bridge. The main girder has a center height of $2.60 \mathrm{~m}$, a roof width of $23.50 \mathrm{~m}$, and thickness of $0.30 \mathrm{~m}$. The full width of 
the box girder is $27.50 \mathrm{~m}$. A two-way cross slope of $2.0 \%$ is set for the deck. Lateral height of standard girder rib is $2.33 \mathrm{~m}$, width of a single rib is $2.00 \mathrm{~m}$. Main beam rib width of side span cast-in-place section changes from $2.00 \mathrm{~m}$ to $3.50 \mathrm{~m}$. The cable-stayed cable system adopts a dense layout, and cable space of the main bridge is $6.00 \mathrm{~m}$, and at side span cast-in-place sections cable space are $4.50 \mathrm{~m}, 6.00 \mathrm{~m}$. The tower is a reinforced concrete "H" tower with a height of $193.00 \mathrm{~m}$, while the heights of top, middle, below pylons are $78.5 \mathrm{~m}, 42.00 \mathrm{~m}, 72.50 \mathrm{~m}$ respectively. Stay-cables are parallel steel wire ropes, which are bundled together into a spiral cluster by multilayer galvanized steel wires of $\varphi 7$.

Auxiliary pier and transition auxiliary pier of main bridge substructure are thin-walled hollow piers. The group pile foundation is adopted, which is made of bored piles $1.50 \mathrm{~m}$ in diameter, and under each pier are 4 piles. The substructure of the approach bridge adopts circular reinforced concrete column piers, whose foundation is also a group pile foundation with a diameter of $1.5 \mathrm{~m}$. Abutments are column abutments with a pile foundation.

D-80-type expansion joints are set at approach bridge abutments, while D-480-type expansion joints are set at the transition piers between the main bridge and the approach bridge. The tower uses C50 concrete, the main bridge girder uses $\mathrm{C} 60$ concrete and the main girder of the approach bridge uses $\mathrm{C} 50$ concrete. The bridge design load is the road-I level; the bridge facade layout is shown in Figure 1.

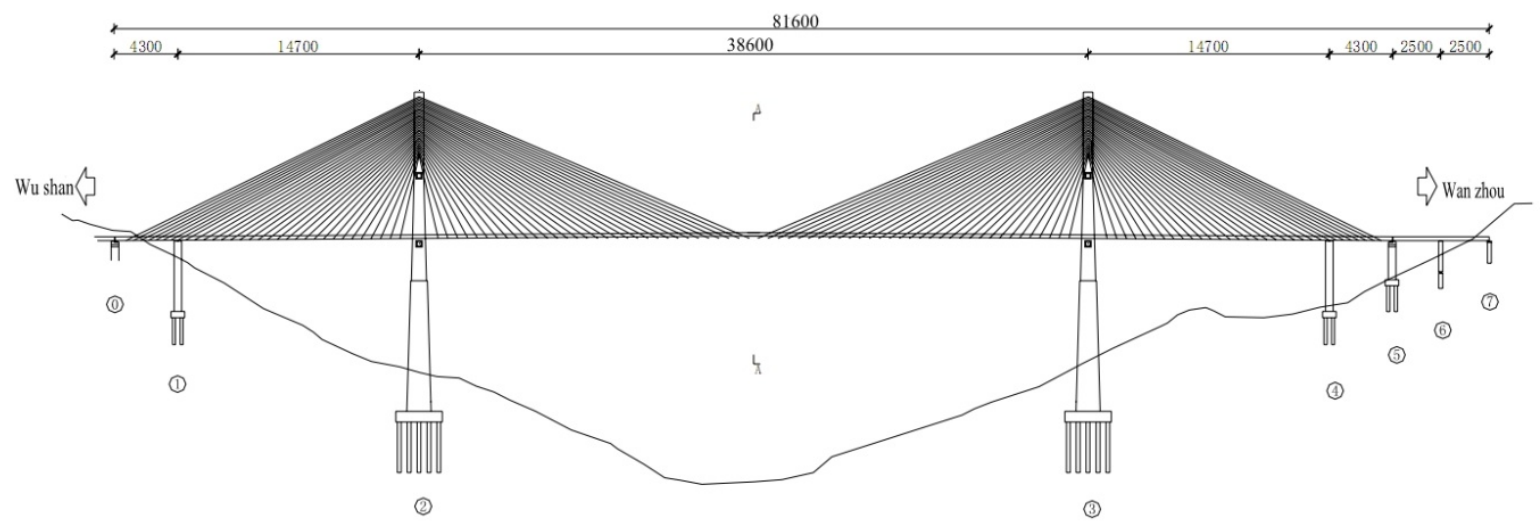

Figure 1. Bridge elevation layout (units: $\mathrm{cm}$ )

\section{Deformation Monitoring Methods and Measuring Points Arrangement}

Based on the bridge situation, this study monitors the plane control network, vertical control points, bridge alignment, cable tower deformation, expansion joints deformation, and cable force of the bridge.

\subsection{Deformation Monitoring Methods}

1) The plane control network

Established as a triangulation network, the plane control network uses a total station with optical prism. After base alignment, measurement is implemented by means of transverse surveys in accordance with Building Deformation Measurement Procedures (JGJ8-2007)[9] level two horizontal control network technology requirement and thus the plane control network monitoring data is obtained.

\section{2) Vertical Control Points}

Vertical datum points are measured by precise levels with indium-steel rulers. Utilizing the national second level measurement method, all leveling routes are formed into closed leveling lines[10].

\section{3) Bridge Alignment Monitoring}

Precision levels with indium-steel rulers are used to measure the bridge alignment. According to level two measuring methods of The National Level One and Level Two Leveling Norms (GB / T 12897-2006), the sight length of leveling, the distance between the front and rear sight, and the number of repeated precision level measurements all conform to the specification requirements for level two precision leveling. Before the measurement, the $\mathrm{i}$ angle of levels are checked first. The datum point and the bridge alignment observation points constitute a closed loop. The observation sequence is behind - front - front - behind for odd points and front - behind - behind - front for even points. The observation data is then balanced. 


\section{4) Cable Tower Deformation Monitoring}

Total Station with optical prism is used to monitor cable tower deformation. According to the level two plane accuracy required in Deformation Measurement of Building Specifications（JGJ 8-2007）[11], the polar method is adopted for measurements.

\section{5) Expansion Joints Deformation Monitoring}

Deformation monitoring of expansion joints includes deck transverse dislocation monitoring and transverse dislocation of joints themselves (steel gap) monitoring on both sides of joints (large and small stake side). Monitoring the lateral dislocation of joints on both sides of the bridge uses total stations with optical prism measurements .Transverse dislocation of joints themselves monitoring e uses steel tape for direct measurement.

\section{6) Cable Force Monitoring}

\section{- Measuring methods}

This cable force measurement uses the Frequency Method. Under circumstances of completely closed traffic, precision vibration pickup is used to pick the environmental vibration excitation signal or attenuated vibration signal after tapping. When testing, make sure the vibration pickup is fixed on the cable to determine the lateral vibration cords. The vibration pickup converts random cable vibration signal into an electric signal. After amplifying electrical signals and send them to dynamic signal acquisition system for sampling and storing, the signals are filtered, amplified and spectral analyzed. The natural frequency of the cable is determined according to the spectrum, and then the cable force is calculated on the basis of the measured vibration frequency.

The Frequency Method is a method that makes use of the correspondence between the cable force and the frequency of the cable and measures the vibration frequency cable when cable length, both ends of the constraints, the distribution of quality parameters are known, and then calculates the cable tension.

For the tensioning stay cable, when the effects of its sag are negligible, the free vibration differential equation without damping is:

$$
E I \frac{\partial^{4} y}{\partial x^{4}}-F \frac{\partial^{2} y}{\partial x^{2}}+m \frac{\partial^{2} y}{\partial t^{2}}=0
$$

Where,

$$
\begin{array}{ll}
x & \text { is the coordinate along the cable } \\
y(x, t) & \text { is the deflection perpendicular to the cable at time } t \\
E I & \text { is the bending stiffness of the cable } \\
t & \text { is time } \\
F & \text { is cable tension; assuming it is uniformly distributed along the cable and does not change with time } \\
m & \text { is mass per unit length of the cable }
\end{array}
$$

The cable force calculation does not consider the impact of cable sag and stiffness. Assuming both ends of cable are articulated. The cable force is calculated according to the following formula:

$$
F=4 m l^{2} \frac{f_{n}^{2}}{n^{2}}=K \frac{f_{n}^{2}}{n^{2}}
$$

Where,
$n \quad$ is the order of cable natural frequency(the number of half-waves within the cable length)
$f_{n} \quad$ is the order $n$ natural frequency of the cable
$l \quad$ is the freedom or flexure cable length
$K \quad$ is the scale factor $\left(\mathrm{kN} \cdot \mathrm{s}^{2}\right)$

\subsection{Test Point Arrangement of Deformation Monitoring}

\subsubsection{Deck Alignment}

The bridge deck alignment monitoring points make full use of the historical monitoring points, and some measuring points are added where the requirements of measurement spacing are not met. Specific arrangement of measuring points is as follows:

The bridge deck alignment monitoring only focuses on the main bridge alignment. Longitudinally, the alignment 
observation points are set at cross sections including L/2, L/4 and the fulcrums of the main bridge as well as cross sections of each stayed cable, and to conform to the requirement that stationing spacing should be no more than $20 \mathrm{~m}$, some alignment observation points are added.

The alignment observation points horizontally along the bridge are set on the bottom of the right and left of the bridge deck against wall, outside the left median concrete fence base. Longitudinally three lines are set, respectively at left, middle and right (line L, Z, R). 384 deck alignment observation points are set for the overall bridge. The observation points are made of stainless steel round head testing nails, implanted with inserted bar glue after drilling holes and marked with red paint. Measuring points plan is shown in figure 2 and 3.

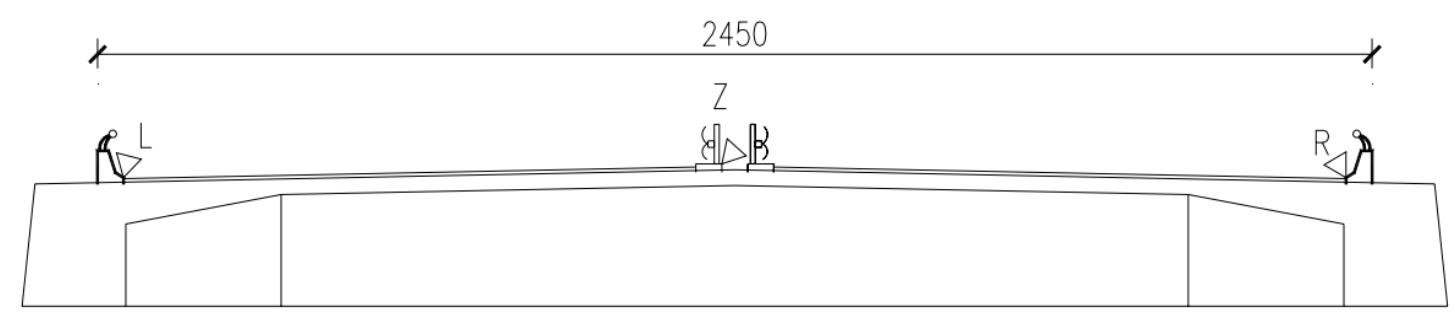

Figure 2. Deck measuring points plan (unit: $\mathrm{cm}$ )

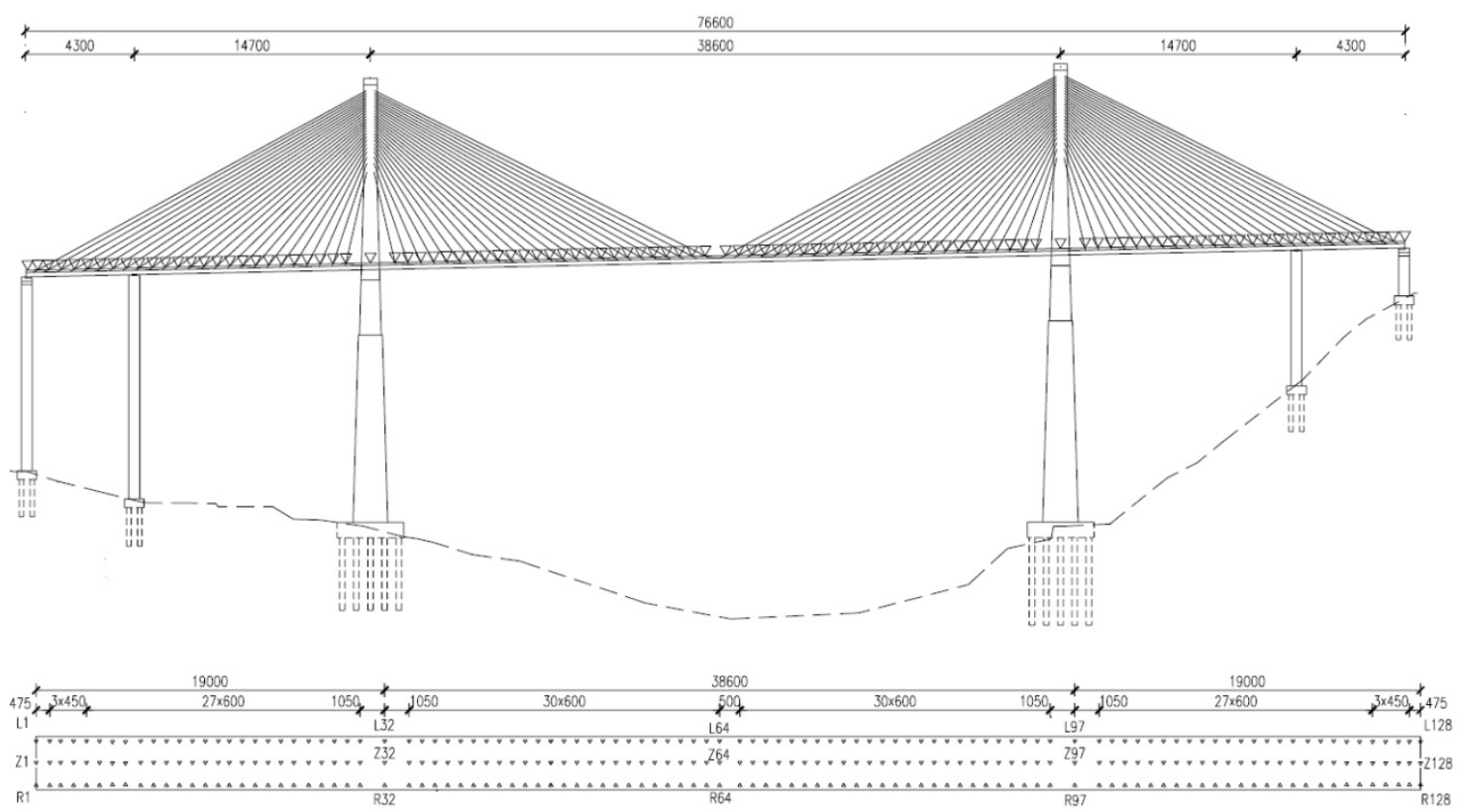

Figure 3. Deck measuring points plan (unit: $\mathrm{cm}$ )

\subsubsection{Cable Tower Deformation Monitoring}

The bridge has two towers (1\# cable tower and 2\# cable tower), and there is one pillar at both sides of them. There are eight deformation observation points set for the two towers in this deformation monitoring and each pillar has 2 observation points. The two observation points are respectively arranged at the top of the pillar and in the middle of pillar near the bridge deck, The measuring point numbers of 1 \# cable tower are from T1-1 T1-4, while the measuring point numbers of 2 \# cable tower are from T2-1 T2-4. The arrangement of measuring points is shown in figure 4. 


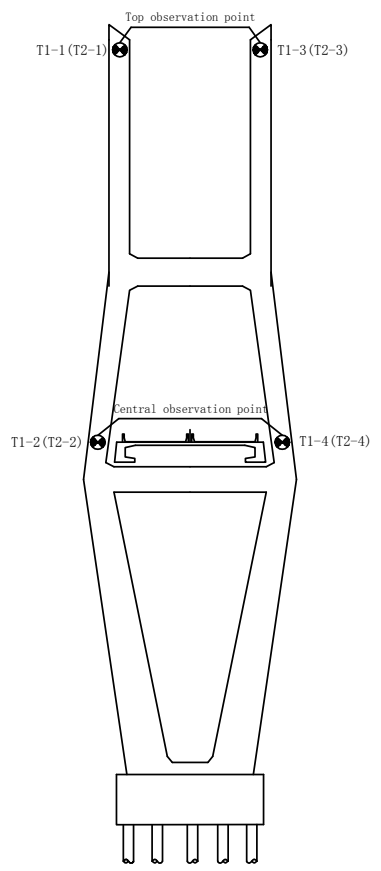

Figure 4. Cable tower measuring points plan

\subsubsection{Expansion Joint Deformation Monitoring}

In this expansion joint monitoring, there is one observation section set at every expansion joint of the main bridge alignment. Laterally the sections are set on the outside of the deck. There are four observation sections and eight measuring points in total. Each observation section has 2 measuring points. Measuring points plan is shown in figure 5 .

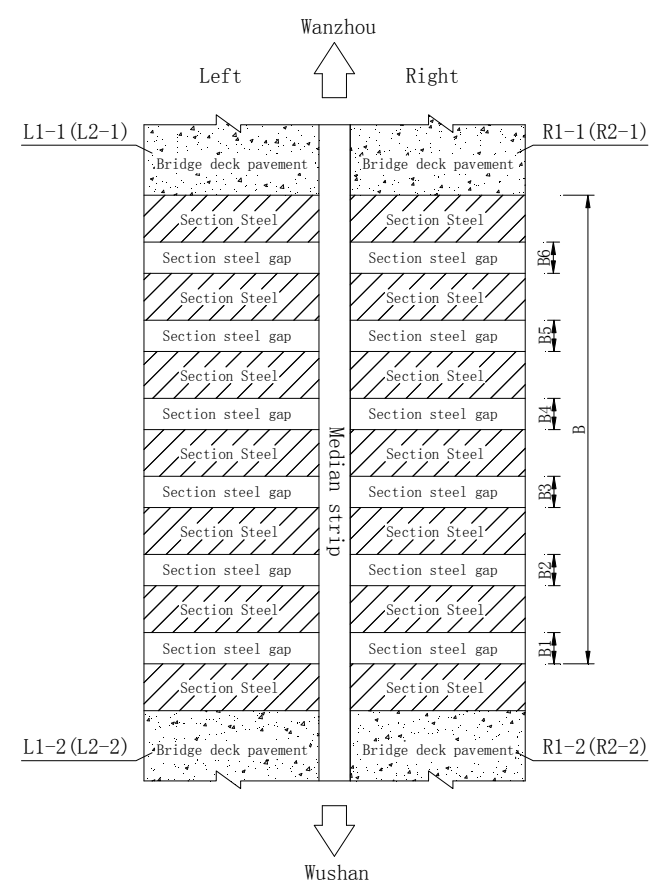

Figure 5. Expansion joint deformation monitoring points plan

\subsubsection{Cable Force Monitoring}

In order to accurately obtain the cable vibration signal under the environment excitation, it is better to set the 
measuring points where the cable vibration amplitude is larger and to avoid the effects of dampers and steel casing as much as possible. According to field test conditions, the cable tension test measuring points are set at the PE casing near the end of the deck. The specific arrangement of measuring points is shown in figure 6.

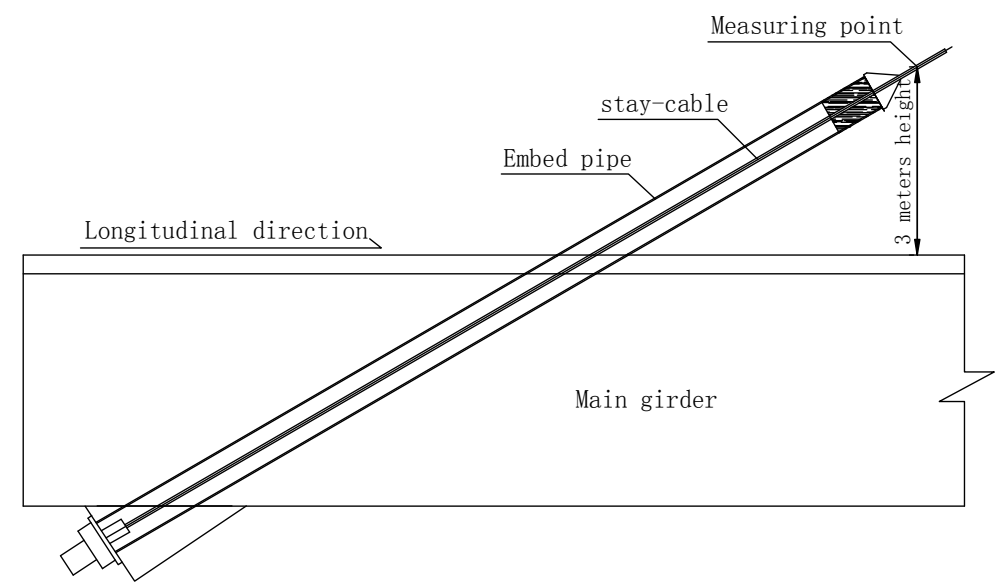

Figure 6. Cable force monitoring points plan

\section{Deformation Monitoring Results and Analysis}

\subsection{Theoretical Calculation of Deformation Monitoring}

According to the material parameters and usage condition of the bridge, modeling and analysis are carried out based on relevant specifications ${ }^{[12]}$ using Midas Civil2010 finite element calculation software. Cables are simulated by truss elements, and the main beam is simulated by beam elements. There are 971 nodes and 708 elements in total. Because in the process of monitoring the traffic is closed, the model does not consider the impact of the moving load. The load types of the bridge model mainly include concrete creep and shrinkage, the loss of pre-stress, temperature change, etc. The discrete graph of structure model is shown in figure 7.

Through calculation and analysis of the model, the theoretical values of the deck alignment, the cable tower deformation and the expansion joint deformation are obtained.

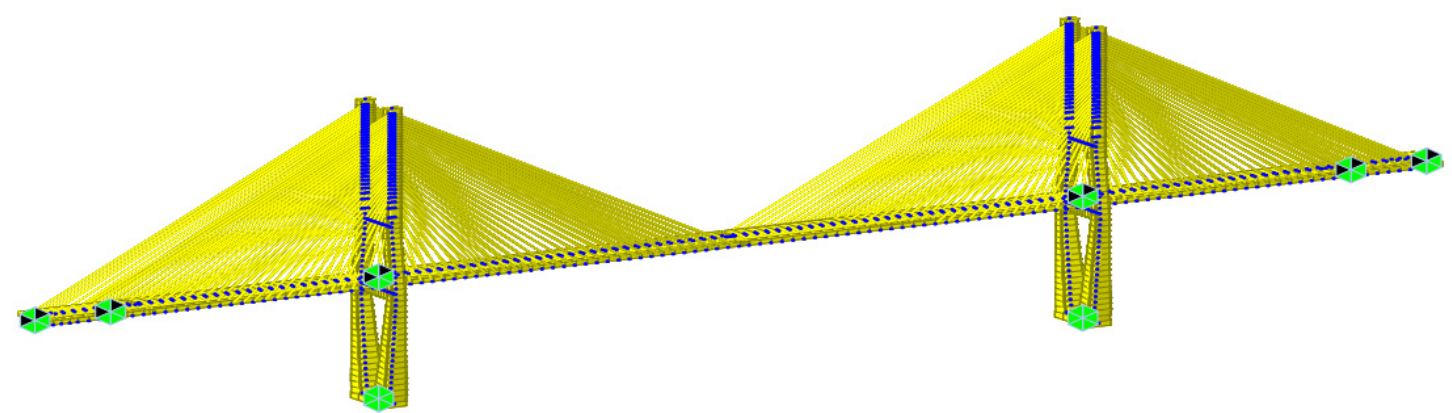

Figure 7. Discrete graph of Midas Civil2010 structure model

\subsection{Comparative Analysis on Theoretical and Measured Values}

With the theoretical calculation result gained from Midas Civil2010, the measured values of bridge deformation can be obtained according to the monitoring content and method of this bridge. Name the two measurements of this bridge as the first and the second period and the interval between two measurements is three months. Comparative analysis is conducted on the measured values and the theoretical value after getting the measured and the theoretical deformation values. The results of vertical deformation comparative analysis of the cable tower, main girder deflection comparative analysis, expansion joint deformation comparative analysis are as follows:

(1) Comparative analysis of bridge deck linear deflection 
Comparative analysis of two measurement results is implemented. The measured deflection is the difference of the relative elevation data of the first and the second period. The positive values represent upwarp, and the negative values represent downwarp. Results are extracted from the finite element program MidasCivil2010 structure model. The comparison of the measured deflection and the theoretical deflection is illustrated in figure 8.

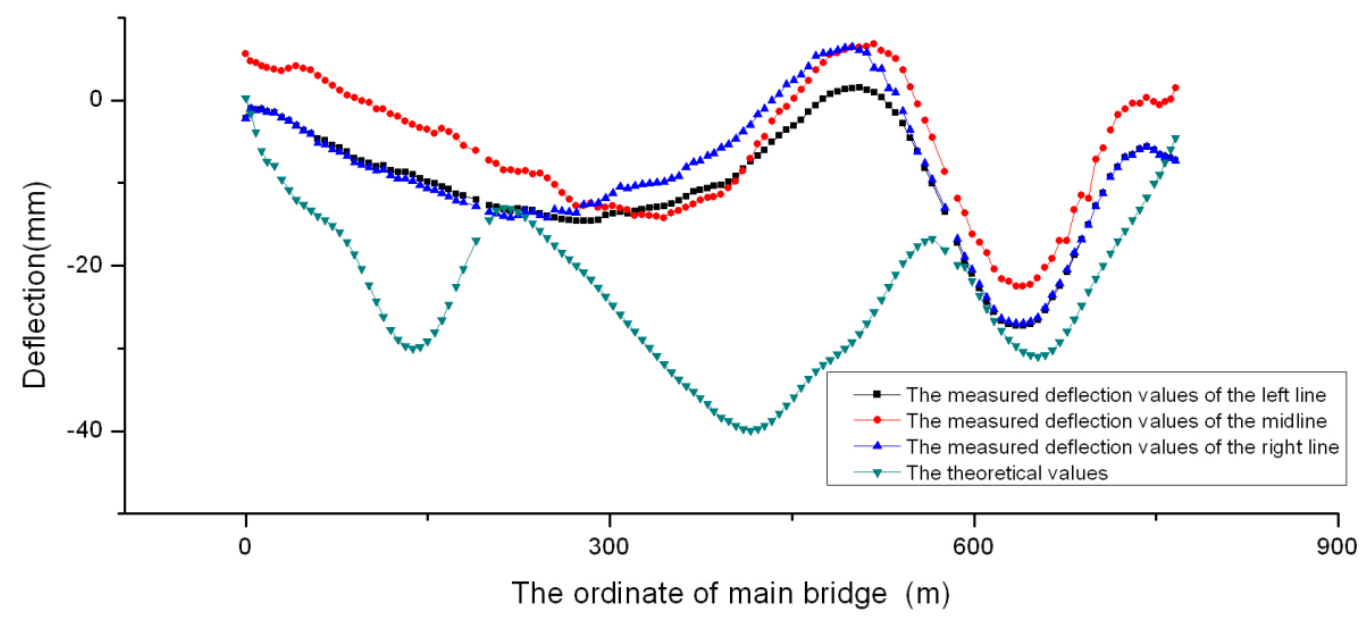

Figure 8. the measured deflection values compared with the theoretical calculation values of the bridge

As is shown in figure 7, of the bridge deck measured deflection, the maximum deflection on the left side is at $0.310 \mathrm{~L}$ of 3 \# cross section and the downwarp is $27.32 \mathrm{~mm}$; the central maximum deflection is at $0.310 \mathrm{~L}$ of 3 \# cross section and the downwarp is $22.49 \mathrm{~mm}$; the maximum deflection on the right side is at $0.310 \mathrm{~L}$ of 3 \# cross section and the downwarping is $27.98 \mathrm{~mm}$. All values are less than the theoretical values.

(2) Comparative analysis on cable tower vertical displacement results

In order to understand the settlement of cable towers and its impact on bridge deck alignment during the monitoring period, the vertical displacement of cable towers are measured. The measured vertical displacement of the cable tower stands for the second and the first phase of the relative altitude. The calculation of cable tower vertical displacement is the theoretical value based on the test condition and has taken into account the overall cooling, creep and shrinkage. Negative value among the cable tower vertical displacement indicates downward distortion. Comparison results are shown in Table 1.

Table 1. Test result of Cable tower vertical deformation (unit: $\mathrm{m}$ )

\begin{tabular}{|c|c|c|c|c|c|c|}
\hline No. & $\begin{array}{l}\text { Measuring } \\
\text { point }\end{array}$ & Location & $\begin{array}{c}\text { Relative } \\
\text { altitude of 1st } \\
\text { phase }\end{array}$ & $\begin{array}{l}\text { Relative } \\
\text { altitude of } \\
\text { 2nd phase }\end{array}$ & $\begin{array}{l}\text { Measured vertical } \\
\text { deformation(10-3) }\end{array}$ & $\begin{array}{l}\text { Calculated vertical } \\
\text { deformation(10-3) }\end{array}$ \\
\hline 1 & T1-2 & $\begin{array}{l}\text { Middle of } \\
\text { 1\# tower of } \\
\text { left bridge }\end{array}$ & 102.43909 & 102.42828 & -10.81 & -12.83 \\
\hline 2 & $\mathrm{~T} 1-4$ & $\begin{array}{l}\text { Middle of } \\
1 \# \text { tower of } \\
\text { right bridge } \\
\text { Middle of }\end{array}$ & 102.398364 & 102.38564 & -12.72 & -12.83 \\
\hline 3 & T2-2 & $\begin{array}{l}\text { 2\# tower of } \\
\text { left bridge } \\
\text { Middle of }\end{array}$ & 102.42920 & 102.41933 & -9.87 & -12.83 \\
\hline 4 & $\mathrm{~T} 2-4$ & $\begin{array}{l}2 \# \text { tower of } \\
\text { right bridge }\end{array}$ & 102.42742 & 102.41803 & -9.39 & -12.83 \\
\hline
\end{tabular}

It can be seen from the test results of main tower observation points that under the condition of cooling 
$17.7^{\circ} \mathrm{C}$. The vertical deformation in central pillar of 1 \# cable tower is $12.72 \mathrm{~mm}$.It is less than the theorical value $12.97 \mathrm{~mm}$. The vertical deformation in central pillar position of 2 \# cable tower is $9.87 \mathrm{~mm}$. It is less than the theoretical value $12.83 \mathrm{~mm}$.

The measured results above indicate that measured vertical deformation for every main bridge cable tower is less than the theoretical value. Thus no main tower has any settlement deformation during the monitoring period.

(3) Comparative analysis on cable tower deviation

In order to understand the deformation of each tower during the monitoring period, the displacement of Cable towers along the bridge is measured. The measured displacements along the bridge are based on the values of the first and the second phase. The measured displacements are converted to values in the axial direction of the bridge. Based on the test condition, the theoretical displacements along the bridge are theoretical values which take into consideration the overall cooling, cable force changes, wind loads affect, creep and shrinkage. The positive values amount them represent the direction towards Wushan. The negative values among them represent the direction towards Wanzhou. The theoretical and experimental results are shown in Table 2.

Table 2. Comparison on theoretical and practical results of Cable tower deviation (unit: $\mathrm{mm}$ )

\begin{tabular}{|c|c|c|c|c|}
\hline No. & $\begin{array}{c}\text { Measuring } \\
\text { point }\end{array}$ & Location & $\begin{array}{c}\text { Measured axial } \\
\text { displacement }\left(10^{-3}\right)\end{array}$ & $\begin{array}{r}\text { Theoretical axial } \\
\text { displacement }\left(10^{-3}\right)\end{array}$ \\
\hline 1 & T1-1 & $\begin{array}{c}\text { Top of } 1 \# \text { tower of left } \\
\text { bridge }\end{array}$ & -10.81 & -12.83 \\
\hline 2 & T1-3 & $\begin{array}{c}\text { Top of } 1 \# \text { tower of right } \\
\text { bridge }\end{array}$ & -12.72 & -12.83 \\
\hline 3 & T2-1 & $\begin{array}{c}\text { Top of } 2 \# \text { tower of left } \\
\text { bridge }\end{array}$ & -9.87 & -12.83 \\
\hline 4 & $\mathrm{~T} 2-3$ & $\begin{array}{c}\text { Top of } 2 \# \text { tower of right } \\
\text { bridge }\end{array}$ & -9.39 & -12.83 \\
\hline
\end{tabular}

It can be seen from the test results of main tower observation points that under the condition of cooling $14.6^{\circ} \mathrm{C}$, the tilt deviation along the bridge on tower top of $1 \#$ cable tower is $43 \mathrm{~mm}$. It is less than the theoretical value $62.35 \mathrm{~mm}$. The tilt deviation along the bridge on tower top of $2 \#$ cable tower is $41 \mathrm{~mm}$. It is less than the theoretical value $62.21 \mathrm{~mm}$. This indicates that the actual stiffness of the tower is stronger than theoretical stiffness as the measured deviation value is less than the theoretical value.

(4) Comparative analysis on expansion joints

Comparative analysis on the theoretical values and the practical values of 4 expansion joints is implemented, the result of which is shown in Table 3 .

Table 3. Comparison on theoretical and practical expansion joint clearance of deck (unit: $\mathrm{mm}$ )

\begin{tabular}{ccccc}
\hline \multirow{2}{*}{ Side } & Expansion joint No. & $\begin{array}{c}\text { Total station } \\
\text { measurements }\end{array}$ & Ruler measurements & $\begin{array}{c}\text { Theoretical } \\
\text { deformation }\end{array}$ \\
\hline \multirow{2}{*}{ The left bridge } & L1\# & 36 & 35 & 55.92 \\
& L2\# & 41 & 41 & 59.57 \\
The right bridge & P1\# & 35 & 35 & 55.92 \\
& R2\# & 41 & 40 & 59.57 \\
\hline
\end{tabular}

According to the expansion joint measurement results, the width of each expansion joint is in an expanding state under the condition of cooling $14.6{ }^{\circ} \mathrm{C}$. The $1 \#$ expansion joint has an expansion of $35 \mathrm{~mm}$, which is less than the theoretical value $55.92 \mathrm{~mm}$. The $2 \#$ expansion joint has an expansion of $41 \mathrm{~mm}$, which is less than the theoretical value $59.57 \mathrm{~mm}$. The measured deformation of expansion joints is less than the theoretical value .In comparison, the expansion volume of $2 \#$ joints is greater than $1 \#$, which demonstrates that each expansion joint of the main bridge in the monitoring period is under normal working condition.

(5) Test results of cable force and comparative analysis

According to the tested natural frequency of stay cables and cable parameters, measured cable force of the bridge is calculated and compared with the design cable force. The results and comparison are shown in Figure 9. 

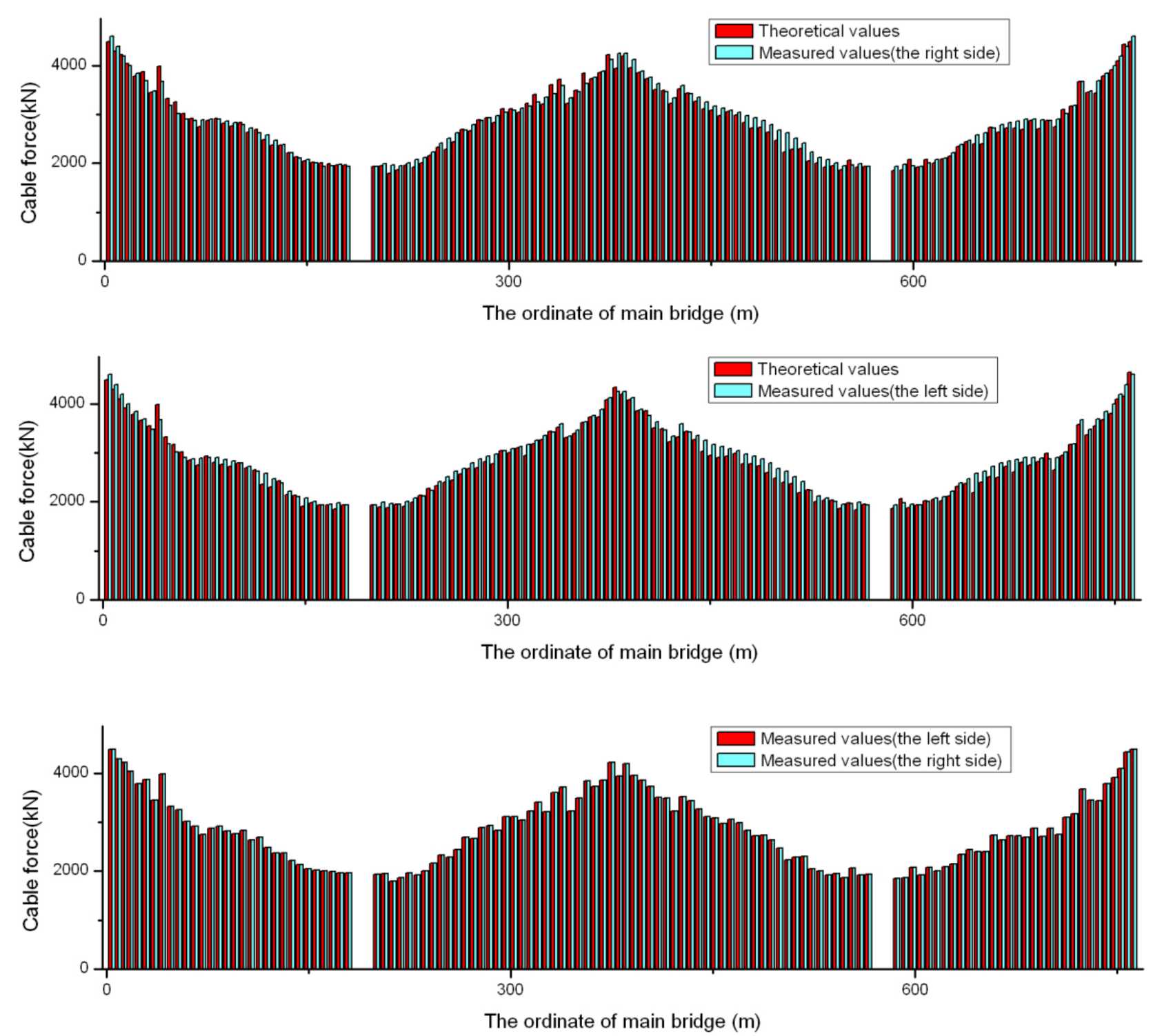

Figure 9. Comparison chart of cable force

Figure 8 shows that the cable force on the left and right sides are consistent under the condition of dead load. The measured values of cable force are consistent with the design values.

\section{Conclusions}

According to the results of comparative analysis on the field measurements and the theoretical values calculated with the finite element software, the following conclusions are reached:

1) Deflection variation of this cable-stayed bridge is basically consistent with the theoretical deflection curve. Measured deflection of each point generally agrees with the theoretical value and all of them are less than the theoretical value.

2) The vertical deformation values in the middle of two cable towers are both less than the theoretical values. It can be initially determined that no settlement deformation of each main tower has happened during the monitoring period.

3) The tilt deviations along the bridge in the direction of the river side on tower top of two cable towers are all less than the theoretical value. It indicates that the real stiffness of the tower is stronger than the theoretical stiffness.

4) Under the field conditions, deformation of expansion joints is less than theoretical value. Thus expansion 
joints are in normal working condition.

5) The cable force on the left and right sides are basically consistent under the condition of dead load. The measured values of cable force are consistent with the design values.

6) According to the measured results, the bridge is the normal working state.

7) Considering that the bridge is merely being monitored under conditions of no moving loads and its structural behavior is evaluated through structural static deformation, it is suggested that a health and safety monitoring system for the main bridge be built when appropriate and real time monitoring of the bridge structural response (parameters like dynamic characteristics and vibration, dynamic strain and dynamic deflection, etc.) be implemented with modern sensor technology in order to obtain various information reflecting structural condition and environmental factors and thus perform comprehensive evaluation of the bridge structural condition.

\section{References}

Chen, Z., Zhang, C., \& Zhou, J., et al. (2013). Study of Cable Force of Construction Control and Alignment Control of Main Girders for Long-Span Railway Cable-Stayed Bridges. Modern Applied Science, 7(9).

GB/T 12898-2006. 《Specifications for the first and second order leveling》[S]. Beijing: Standards press of china, 2006.

He, X. H., Yu, Z. W., \& Chen, Z. Q. (2008). Finite Element Model Updating of Existing Steel Bridge Based on Structural Health Monitoring. Journal of Central South University of Technology, 15, 399-403. http://dx.doi.org/10.1007/s11771-008-0075-y

Jang, S., Jo, H., \& Cho, S., et al. (2010). Structural health monitoring of a cable-stayed bridge using smart sensor technology: deployment and evaluation. Smart Structures and Systems, 6(5-6), 439-459. http://dx.doi.org/10.12989/sss.2010.6.5_6.439

JGJ 8-2007. 《Building Deformation Measurement Procedures》[S].Beijing: China Building Industry Press, 2007.

JGJ 8-2007. 《Code for deformation measurement of building and structure》 [S] Beijing: China Building Industry Press, 2007.

JTG D60-2004. 《General Code for Design of Highway Bridges and Culverts》[S]. Beijing: Standards press of china 2004.

Mosbeh, R. K., \& Hui, L. (2009). Monitoring of Bridge Deformation Using GPS Technique. Journal of Civil Engineering, 13(6), 423-431.

Pradipta, B., \& Sanjay, A. C. (2011). Structural Health Monitoring of a Steel Railway Bridge for Increased Axle Loads. Structural Engineering International, 5, 210-216.

Roberts, G. W., Meng, X., Dodson, A. H. (2000). Structural dynamic and deflection monitoring using integrated GPS and triaxial accelerometers[C]/Proceedings of the 13th International Technical Meeting of the Satellite Division of The Institute of Navigation (ION GPS 2000), 59-68.

Vurpillot, S., Krueger, G., \& Benouaich, D., et al. (1998). Vertical deflection of a pre-stressed concrete bridge obtained using deformation sensors and inclinometer measurements. ACI Structural Journal, 95(5).

Zengshun, C, Jun, S, \& Cheng, Z., et al. (2013). Study of Different Construction Processes Affecting the Installation of Appropriate Cambers for Long-Span Railway Cable-Stayed Bridges. Modern Applied Science, $7(8)$. http://dx.doi.org/10.5539/mas.v7n8p89

\section{Copyrights}

Copyright for this article is retained by the author(s), with first publication rights granted to the journal.

This is an open-access article distributed under the terms and conditions of the Creative Commons Attribution license (http://creativecommons.org/licenses/by/3.0/). 